\title{
CONFLICTO DE VALORES EN LA DISPUTA EN TORNO AL NEOLIBERALISMO*
}

\author{
José I. González Faus**
}

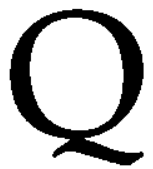

uizá deba comenzar precisando desde dónde hablo. Está claro que yo no hablo como economista, porque no lo soy. Tampoco hablo, sin mas, como teólogo, aunque eso es lo que cicen que soy. Quisiera hablar como ser humano. $Y$, si se prefiere como ser humano: igual que el paciente le puede hablar al médico.

Mi experiencia humana es que la utopía plena es una armonía de valores que, de suyo, no parecen armonizables. Creo que ésta es una experiencia bastante general Jordi López hablaba, incluso respecto a la economía, de "crear y repartir", "producir y no dañar", etc...). Quizá por eso la tradición ha calificado a Dios con frecuencia como "la armonía de contrarios".

En estas condiciones, creo que a cualquier sistema o situación que se analice sólo se le puede exigir:

- un esfuerzo armonizador,

- Publicado en Revista CHRISTUS Nº 70, oct.nov. 1994.

* Teólogo español; profesor visitante de la UCA. 
- una coherencia en los valores que prioriza, distante de todo oportunismo,

- y razones convincentes de por qué prioriza estos o aquellos valores.

Pues bien: en este marco de pensamiento quisiera proponer dos tesis y algunos ejemplos de ellas.

La primera afirmación es que los neoconservadores no buscan la armonía de los valores humanos ni son coherentes respecto a aquéllos que privilegian.

Más bien habría que decir que eligen unos valores humanos para el campo económico-social, y otros bien diferentes para el político-cultural; o bien, dan por supuesta esa armonía de modo mecanicista o por alguna especie de "mano invisible" que dispensa de buscarla1.

Ello es quizá lo que origina esa doble denominación contraria: se les designa a la vez como neoliberales y neoconservadores. Y es que lo de "liberales" alude al terreno económico, y lo de "conservadores" al terreno cultural. Luis de Sebastián ya mostró en un Cuaderno muy citado (La gran contradicción del liberalismo moderno) cómo los liberales de hoy difieren de los antiguos en que éstos luchaban por la iniciativa humana frente al monopolio de reyes y nobles, mientras que los modernos defienden el monopolio del capital y las finanzas frente al trabajo. De libertad contra monopolios se pasa a libertad para monopolizar.

Algo de esto es lo que se refleja ya en el mero título de algunas obras. D. Bell habla de "las contradicciones culturales del capitalismo", y un título así da por supuesto que el capitalismo sólo funciona mal en el campo ético-cultural; ni siquiera considera que las contradicciones puedan manifestarse también en el campo económico2. Y Novak hace la apología del Capitalismo democráti-

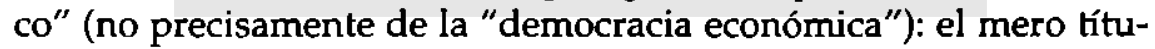
lo ya sitúa el campo de lo democrático en el ámbito de los sistemas políticos, pero lo mantiene fuera de los sistemas económicos (si "democracia" significa "poder del pueblo", lo de "capitalismo" da a entender que no hay poder del pueblo en lo económico).

J. M. Mardones ofrece una rápida catalogación de esas series de 
valores exclusivizados, de los que luego analizaremos algunos en los ejemplos. Pero veamos ahora la enumeración:

-Para el mundo económico: cálculo, jerarquía, rentabilidad, eficacia, poder de convicción, trabajo, disciplina laboral...

-Mientras que para el mundo político-cultural: solidaridad, moderación, participación, descentramiento del propio interés, responsabilidad, bien común...

O más crudamente: se ha propugnado para la producción el individualismo, la ilimitacion, la dureza y el "todo es experimentable". Mientras que para la convivencia se propugnaba la solidaridad, la austeridad, la piedad y los límites a la experimentación. O con otras palabras: a la hora de producir rigen la ley del deseo y la libertad sin límites. Pero se pretende que, a la hora de convivir, se controle el deseo y se pongan límites a la libertad.

Puede discutirse si se trata aquí de una profunda incoherencia del sistema (que es lo que dicen sus detractores) o si es que los diversos campos poseen diversas lógicas inmanentes (que es lo que dicen sus defersores). Puede preguntarse también si esta segunda postura no implica una profunda esquizofrenia de fondo en la vida humana. Y sería interesante prolongar la discusión por ahí. Pero a mí me parece que ello no es necesario por el momento, pues la caractérística de nuestra hora histórica, que vamos a comentar en la tesis siguiente- y que ha generado la ofensiva neoconservadora - reside precisamente en que esa separación radical ha caído. Se ha producido una especie de repatriación o travestismo, o una babel de valores por la que se aplican al campo político o cultural pautas que hasta ahora parecían reservadas al campo económico.

Puedo ilustrar esto con una anécdota que me ocurrió en mis primeros años de práctica pastoral. Vino a verme un señor profundamente afectado por una conversación con su hijo mayor. Se trataba del clásico empresario de aquellos años sesenta que había prosperado económicamente en aquel famoso despegue de nuestro plan de desarrollo. No puedo dudar de su buena intención: era un católico convencido, tirando a franquista, aunque dispuesto a aceptar una democracia siempre y cuando no implicara demasiados riesgos, y que había procurado ganar dinero para llevar a sus 
hijos a colegios religiosos, etc., etc. Pero cuando los hijos comenzaron a ser mayores, en aquel 68 variopinto e inesperado, y con las primeras posibilidades de salida al extranjero y demás, comenzó a ver que sus conductas "morales" se apartaban bastante de lo que cabría esperar del clásico alumno de los jesuitas perteneciente a una familia católica.

Haciendo un esfuerzo supremo (porque ya es tópico que en aquellos tiempos los padres nunca hablaban a los hijos de temas sexuales), el padre se decidió a tener una larga conversación con el hijo mayor. No sé muy bien lo que le diría pero sí recuerdo la respuesta desabrida del chico, con esa mezcla de lucidez e inconciencia cruel que tiene a veces la gente joven: "a fin de cuentas, no veo por qué yo he de tratar a las mujeres con más respeto que el que tú has usado con tus obreros durante toda tu vida".

No es dificil imaginar el dolor sobrecogido de aquel hombre, pero yo cito la anécdota, porque ya entonces me pareció descubrir en ella un significado histórico: aquel muchacho percibia una incoherencia entre las conductas que le querían imponer a él en el terreno sexual y las que él habia mamado como vigentes en la profesión paterna. Se preguntaba por qué había de normar su vida personal con unos valores que no parecían tener ninguna cabida en el campo más básico de la vida, y, por su cuenta, había sacado la conclusión: si el deseo, el individualismo o la desconsideración hacia el otro son claves axiológicas del mundo económico, ¿por qué no han de pautar toda la vida de la persona?3.

No sé si esta anécdota visibiliza bien lo que antes he llamado "esquizofrenia axiológica", y la consiguiente -y reactiva"repatriación de valores". Quedémonos otra vez con el enunciado de la tesis: el neoconservadurismo no busca propiamente una armonía valoral, sino que cree en una división y la reclama. Esta es la herencia que hemos recibido junto con un determinado modo de configurar la historia. $Y$, en este sentido, los neoconservadores apelan con razón a las tradiciones patrias y a "los ideales de los antepasados que engrandecieron a este país", etc., etc.

Pero precisamente esa dualidad es la que hoy se ha vuelto imposible. $Y$ con esto entramos en nuestra segunda tesis. Intentemos ver por qué. 
La novedad de nuestro momento histórico me parece percibirla en que han dejado de funcionar una serie de factores que, hasta ahora, contribuían a mantener esa disociación de valores. Enumeremos algunos:

a) La mentalidad de guerra. Gracias a ella, gracias al "enemigo absoluto" que era el consumismo y a la necesidad de estar alerta contra él, funcionaban en el campo personal una serie de demandas (necesidad de sacrificio, de renuncia, de heroísmo, etc) a las que hoy no se les ve ningún sentido.

b) El factor religioso ha funcionado también como justificador y origen de esa mentalidad. Y aquí creo que tiene plena aplicación de tesis de $\mathrm{M}$. Weber sobre la mentalidad calvinista y la ética del capitalismo, (sólo con que añadamos que ese "calvinismo" no es exclusivo de Calvino). Baste recordar que la mentalidad de guerra antes evocada, nosotros la hemos vivido como "civilización cristiana" contra "comunismo ateo".

Pues bien, en mi modesta opinión, hoy, con la caída del Este y la secularización de Occidente, se han perdido los ejes vertebradores de aquella antigua mentalidad.

Añádase a esto (para aquéllos que consideran que la secularización es un fenómeno sólo momentáneo) la recuperación del Dios de Jesús: el Dios de los evangelios no es un Dios justificador de los sistemas, sino más bien subversivo, de ellos; no se limita a pedir beneficencia al rico y resignación al empobrecido, sino que reclama austeridad solidaria a los enriquecidos y solidaridad combativa a los pobres. Y además no es un Dios sólo para algún campo "religioso" o numinoso de la vida, sino para todos los ámbitos de ella.

Y añádase, por último, el factor económico, que comentaré más adelante en el ejemplo 5.

Esta enumeración de factores nos permite concluir que los neconservadores han percibido con exactitud que el tejido social está amenazado. Pero diagnostican mal: creen que ello es debido sólo a que "se han perdido unos valores", y hasta culpan de ello al poco celo de las iglesias. Pero quizá se debe más bien a que se han aplicado al campo de "la cultura" valores que ellos reservaban en 
exclusiva al mundo económico (ausencia de barreras, eficacismo, ignorar al otro...). Este trasvase es ya irreversible, y, por tanto, la recuperación de valores no podrá hacerse dejando intacto el mundo de la economía. Las contradicciones culturales del capitalismo no son solamente culturales: son contradicciones globales, de todo el sistema, de toda la sociedad.

Hasta ahora, una postura socialdemócrata podía quizá paliar la percepción de este diagnóstico, porque precisamente la socialdemocracia intenta en algún sentido evitar esa esquizofrenia de los valores. Pero la crisis actual de la socialdemocracia y el liberalismo "puro y duro" de los reaganianos y de los "Chicago boys", han acabado por dejar más al descubierto la enfermedad del sistema.

Aquí podríamos concluir, pero creo que la exposición ganará en claridad y envergadura si analizamos un poco más despacio algunos valores concretos para ver cómo funcionan en el campo económico y cómo funcionan (o dejan de funcionar) fuera de él. Voy a analizar nada menos que siete ejemplos.

\section{El valor-dinero}

o hay inconveniente en reconocer que el dinero es un valor,
dado que puede ser un medio eficaz y rápido. Es, no obstante, un valor sumamente peligroso y que necesita ser compensado allí mismo donde se afirma como valor. El Nuevo Testamento escribe - como ya sabemos- que "la raíz de todos los males es el ansia de dinero". Y puede que sea útil comparar esta frase con el siguiente párrafo de M. Novak, que se considera a sí mismo cristiano y teólogo:

"Pocas sociedades han inventado un incentivo tan inocente en sí mismo, tan automultiplicador, tan creador de vínculos sociales y que tanto depende de la salud global de la sociedad (como el dinero). Por todos estos motivos, parece equivocado suponer que el espíritu competitivo por el dinero sea el peligro espiritual más mortal para la humanidad" (El capitalismo democrático, 374).

Fijémonos en los adjetivos: se trata de un valor no peligroso en sí mismo, sino absolutamente "inocente". Se le considera "automultiplicador", que es un adjetivo estrictamente teologal, porque sólo Dios puede ser causa de sí. Es cierto que "el dinero llama al dine- 
ro"; pero nuestro autor evita preguntarse si ello es debido a la naturaleza del dinero o a la pasión del hombre por él. Como también evita preguntarse si esa automultiplicación nominalista no será algunas veces el reverso de otro proceso por el que el dinero siempre se acumula empobreciendo a otros. Finalmente, considera que en él reside la salud "global" de la sociedad; y "global" incluye a todos los miembros de ella; el autor piensa seguramente que también es salud para los pobres el que, cuando hay mucho dinero, caigan más migajas de la mesa de los epulones, con lo cual puede ser que llegue alguna migaja más a los Lázaros, incluso después de haber saciado a los perros del epulón. Pero, en realidad, muchas veces no ocurre ni eso: ocurre que sólo se considera como miembros de la sociedad a aquéllos que tienen dinero. Los demás constituyen una especie de enclave que tendrá el sentido de un gueto de Varsovia o de un "apartheid" de Sudáfrica, aunque no tenga su misma forma. Uno no puede menos de pensar, al leer la argumentación de M. Novak, en aquellos viejísimos versos de la Eneida de Virgilio:

"Hambre idólatra del oro, qué obligas a hacer al hombre!"4

Pero no quisiera que la cita de autores tan antiguos nos desviara del aspecto específicamente moderno del problema. Es evidente que el hambre de oro ha existido siempre, porque la naturaleza humana es, más o menos, la misma siempre. Pero, como escribe T. Todorov:

"El deseo de hacerse rico ciertamente no es nuevo, y la pasión del oro no tiene nada de específicamente moderno. Pero lo que sí es más bien moderno es esa subordinación de todos los demás valores a éste" 5 .

Esa exclusivización del valor es la que está vigente en nuestro sistema económico y, por eso, de entrada se acepta crear cosas como la esclavitud, el hambre o la destrucción del planeta, con la esperanza de que luego, cuando tengamos ya mucha riqueza, seremos capaces de arreglar con ella esos desaguisados. En cambio, en el campo "cultural" se combate esa exclusividad: se dice que no hay que ser mezquinos, que hay que ser (o dar imagen de) generosos, etc., etc. La aguja axiológica gira aquí casi hasta el extremo opuesto. $Y$ hasta ahora eso ha funcionado, y se ha mantenido esa divi- 
sión de valores según los campos; en la fábrica, amor al dinero; en la vida cotidiana, desprendimiento de él.

Si esto es una incoherencia, o si es que la realidad es así de dicotómica, podemos dejar de discutirlo. Lo que ahora quisiera añadir es la sensación de que esa división de campos ya no funciona; hoy se alardea de amor al dinero o, por lo menos, como dijo una vez Mario Conde, "ha dejado de ser pecado". Quizá recordéis que, cuando C.J. Cela ganó el Nobel de literatura, le hicieron una entrevista por televisión en la que (con esa insustancialidad propia de este tipo de entrevistas ocasionales) el periodista le preguntó si pensaba dedicar el dinero o parte de él a alguna fundación o ayudar a alguien, etc. Y Cela, haciéndose el gracioso, contesto: "no señor, jes mio!". Creo que hace unos pocos años nadie se habría atrevido a dar una respuesta como ésa: quizás el interrogado había pensado así y habría actuado luego en esa dirección; pero no lo habría dicho: habría fingido generosidad o echado pelotas fuera ("ya lo estudiaremos", etc). Y si hubiese respondido como Cela, habría perdido mucha imagen. Ahora manifestar esa forma de avidez ya no resulta indecoroso, sino simplemente divertido. Y quizás esto se deba a que somos menos hipócritas que antaño. Pero (en la medida en que es cierta aquella definición de que la hipocresía es el homenaje del vicio a la virtud") se debe también a que la generosidad está tan despreciada valoralmente en el campo de la convivencia como en el campo de la economía. Parece, pues, que aquí se ha roto la dualidad de campos y valores, y que la "lógica de un campo ha invadido el otro".

$\mathrm{Y}$ vamos con otro ejemplo.

\section{El valor-información}

Tasta qué punto es un valor la información en el campo políti1 co, cultural, etc., no hace falta describirlo. Quizá baste con evocar simplemente el siqnificativo título que le dedica $A$. Toffler: El cambio del poder. Todos sabemos que los periodistas apelan a veces a su "deber de informar" para justificar toda clase, no sólo de riesgos, sino de tropelías, faltas de respeto o violaciones de la intimidad. Es posible que, en algunas ocasiones, estemos incluso demasiado informados o demasiado asediados por informaciones inútiles. Esto, por lo que toca al campo político-cultural. 
Pero en las áreas económicas la información es infinitamente más escasa, y se procura controlarla al máximo. Y no me estoy refiriendo a esas informaciones que pueden llamarse privilegiadas porque desencadenan conductas incontrolables ("no habrá devaluación de la peseta") o "aquellos terrenos se van a revaluar debido a tal plan u ordenanza municipal", etc.). Si sólo se tratase de esto, sería lógica la restricción, porque todos los valores son parciales y necesitan ser complementados. Pero ahora me refiero a otras informaciones más generales y nada privilegiadas.

Por ejemplo: ¿habéis notado qué poco se habla ya de Nicaragua? Una vez se ha conseguido desacreditar y derribar al sandinismo los controladores oficiales de la información deciden que Nicaragua ya no es noticia. $Y$ con ello dejan en nuestro inconsciente la sensación de que ya esta yendo mejor. $Y$, sin embargo, no es así: Nicaragua está hoy igual o, en muchos aspectos, peor. Será cierto que los ricos están mejor y ya pueden ir a Estados Unidos a hacerse un lifting. Pero lo que llaman allí la canasta básica (el mínimo vital) cuesta ya más de 800 córdobas, mientras que el salario medio (no el mínimo) está por los 300 córdobas. Y yo puedo dar el testimonio siguiente: he estado cuatro veces en Nicaragua: la primera (1980) las calles de Managua están invadidas de niños ocjosos mendigando. He contado en algún sitio que alguien me dijo: acabar con esto es uno de los desafíos de la revolucion. Cuando volví en 1982 resultaba increíble, pero no había niños por las calles de Managua. Volví a pasar en 1985, poco después de comenzada la guerra de la contra: comenzaban a reaparecer los niños por las calles. $Y$ he estado hace poco en noviembre del 91, para ver las calles de Managua otra vez plagadas de criaturas ociosas, golfeando o mendigando. Esas criaturas que luego serán carne de cañón para esos que hacen limpieza de las ciudades matando niños, como acabamos de oir de Brasil y Colombia. De estas cosas no informa nadie. $Y$ ya es significativo el que yo mismo me sienta ahora en la necesidad de aclarar que, al decir esto, no estoy defendiendo a los sandinistas (que cometieron errores importantes e insuficiencias éticas lamentables). Sólo estoy queriendo decir que tan noticia como los errores de los sandinistas deberían serlo las aberraciones de sus sucesores. Peio ésta sería una información peligrosa para el sistema económico. 
También podemos leer algunas veces que México está "saliendo de la crisis económica", lo cual, a niveles macroeconómicos, puede ser cierto, y es lógico que se diga; pero nadie informa de los precios humanos que ha habido que pagar para salir de esa crisis (en hambre de los pobres $Y$ en pérdida de poder adquisitivo de los más débiles): el poder adquisitivo de los salarios se, ha reducido desde 1983 en, un 63\%, mientras que los grandes capitales han crecido desmesuradamente, $y$ hay acciones que han incrementado su valor en un $176 \%$. Si los locos de Sendero Luminoso no hubieran matado a María Elena Moyano, no habríamos oído decir a la prensa que la política Fujimori ha reducido la inflación pero al precio de pasar en Perú, de siete millones dé hambrientos, a doce millones (ver El Mundo 23 de febrero de 1992). Y, lógicamente, proclamar un logro sin decir su precio distorsiona totalmente la informacion, porque convierte en un éxito lo que, a lo mejor, no era más que una crueldad7. Para mí, la mayor inhumanidad de los etarras radica en que, aun en el caso de que un día lograran ganar su guerra y proclamar la independencia de Euskadi, nunca se justjficará una independencia a ese precio de barbarie y de sangre. $Y$ esto mismo lo reconocen ellos tácitamente, porque se puede suponer lo que harían si un día ganasen su supuesta guerra: ocultarían todas sus víctimas y toda la informacion sobre ellas.

Pues igual nosotros: en nuestro sistema el derecho a la información (que equivale a la posibilidad de decisión) será un valor en los campos políticoculturales de la vida, pero no lo es en el campo económico. Y esta incoherencia la comete un sistema que -como he dicho al principio- pretende hacer de la "libertad de informacion" uno de sus valores supremos.

Vamos con otro ejemplo.

\section{La ayuda a los pobres}

T a dualidad en este campo está magníficamente expresada en Luna conocida queja de Helder Cámara: "Si quiero ayudar a los pobres, me llaman santo; si pregunto por que existen, me llaman comunista". Efectivamente: los pobres son un valor sólo en el campo asistencial. Teresa de Calcuta es seguramente una santa. Pero nuestro mundo la aplaude, no porque le importe la santidad sino porque ella no cuestiona el sistema. $Y$ hasta hacemos grandes es- 
fuerzos para ayudarla, porque esa ayuda no sólo tranquiliza la conciencia personal, sino que también protege la justicia estructural.

Pero la consideración a los pobres no es - no puede ser- un valor en el campo económico. Y esa consideración significaría para mí estas tres cosas: a) no producirlos; b) intentar producir oara ellos; y c) oírlos: darles al menos más voz, ya que tienen menos dinero (en mi modesta opinión, el papa no tendría que escuchar lecciones éticas de Mario Conde, sino más bien de sus víctimas. Pero todos sabemos que las cosas funcionan al revés).

Y si parezco duro aquí, es porque la pregunta de Helder Cámara de por qué existen los pobres es para mú muy seria y muy última, y lo ha sido también en la tradición espiritual cristiana. $Y$ yo sólo le veo tres respuestas: o la causa es la realidad (y si la realidad es intrínsecamente injusta, digámoslo así de claramente y dejemos estar toda lucha por la justicia en todos los campos); o la causa es su propia culpa (pero esta respuesta contradice mi propia experiencia si se la quiere erigir en causa total o simplemente mayoritaria); o la causa es nuestro sistema (lo cual es algo muy distinto de nuestra "realidad", aunque hoy por hoy la enfermedad esté tan metida en el sistema que ya parezca incurable); o en esa causa participan los tres factores a la vez: lo cual ya sería una afirmación suficiente, porque al menos, nos obliga a reconocer $-\mathrm{y}$ a eliminar- la injusticia inherente al sistema.

\section{Los valores de eficacia y gratuidad}

Tumanamente hablando, hay valores que son a veces comple1 mentarios, o incluso superiores, a la máxima eficacia. Una de las grandezas de la democracia reside en reconocer esto, aunque ese reconocimiento la haga muchas veces menos "eficaz", más lenta, más inerme pero también la hace más humana. La democracia lucha desde la debilidad de la grandeza moral: hasta el enemigo tiene sus derechos. Y la democracia acepta estos recortes.

Pero todo eso no vale en economía, donde sólo se lucha desde la fuerza de la codicia, donde perder la máxima eficacia y el máximo rendimiento es ser un economista ruinoso, y donde toda la gracia está en hacer, o consumir, más de lo actualmente posible 
para de esta manera, obligarse a producir por encima dé todo. Entrar en esta rueda que sacrifica todos los valores humanos a la eficacia es "entrar en esta sociedad". Y el que no quiere entrar en esta rueda nunca acaba de ser una persona como todas, siempre será un estrambótico o un marginal.

O con otras palabras: el sistema económico está montado sólo sobre la competitividad. Esto es lo que le hace tan sumamente eficaz. Ahora bien: la competitividad es un valor que sólo es tal "en pequeñas dosis", es como la sal o cualquier otro condimento; si se la exclusiviza o exagera, más todo lo demás. $Y$ entonces su eficacia será tan grande a la corta como discutible a la larga. En pequeñas dosis puede dar a las cosas una tonalidad lúdica; en dosis masivas convierte al hombre en "un lobo para el hombre".

$Y$, ya que estamos en el 92, no quiero dejar pasar estas alusiones sin hacer una referencia a la falsificación de los juegos olímpicos, que ya no tienen nada de su espiritu primitivo, cuando todavía eran juegos. Ahora la competitividad se ha desbordado $y$ exclusivizado tanto que, para triunfar, se estropean cuerpos, se idiotizan mentes, se prostituyen relaciones y se convierten tonterias o pequeñeces en especialidades. De "juegos" han pasado a ser "negocios" olímpicos.

\section{La primacía de la persona}

También aqui me parece detectar una incoherencia curiosa: en 1 el mundo político y en el de la relación personal la persona es un valor sacrosanto e insustituible. Pero en el mundo económico y en la empresa, la persona es un número, una cifra que puede estar de más o ser intercambiable y, al decir esto, no me estoy refiriendo sólo a los inmigrantes o a los africanos del Maresme La sustitución de la dignidad personal por una referencia numérica vale también para esos a quienes he oído llamarse 'esclavos muy bien pagados" $"$ altos cargos de la banca que ganan un gran sueldo, pero que pagan por él el precio de no ser personas para sus jefes, sino solo objetos exprimibles. Como me decía no hace mucho uno de ellos: "no puedo ser padre, ni esposo, ni persona interesada por la cultura; sólo puedo ser un empleado bancario Disponen de todo mi tiempo y de todas mis energías (salvo lo indispensable para que me reponga un poco y puedan seguir chupándome). Si me quejo, 
me callan la boca con más dinero. Pero si me planto y digo que lo que yo quiero no es más dinero, sino más tiempo para dedicarlo a otras facetas de la vida como pueden ser mi mujer, mis hijos o mi desarrollo humano, entonces se perfectamente que en el Banco hay más de 200 aspirando a mi puesto, acabaré siendo marginado y no podré dar a mi familia el nivel de vida en que yo mismo les he introducido y que me siento obligado a darles".

Podría contar algún testimonio más, pero me temo que incluso podría ser reconocido el interesado. Quedémonos con esa curiosa incoherencia: en la sociedad somos personas; en la empresa, no. ¿Es esto normal? ¿0 puede acabar llevando a la conclusión de que tampoco tenemos por qué serlo en la sociedad?...

$Y$ en el contexto de estos dos ejemplos 4 y 5 (eficacia y respeto) es donde se sitúa para mí el problema ecológico, sobre el que me gustaría decir una palabra.

La economía capitalista nunca aceptó que ella tuviera que acatar un valor-respeto armonizable con el valor-eficacia. Las reivindicaciones del respeto son siempre desautorizadas como cosa de ingenuos o de inexpertos, hasta que llegó un momento en que esa falta de respeto afectó no sólo a las personas (que éstas nos dan igual, porque no creemos eso de que son sagradas, etc), sino que afectó también a la Naturaleza. Y la Naturaleza nos está respondiendo con más dureza que la que podrían emplear los condenados de la tierra. Así nos hemos dado cuenta de que estábamos cargándonos, no sólo a unos cuantos seres humanos, sino nuestro hábitat y nuestro planeta. $Y$ así ha nacido el problema ecológico. Yo no entiendo mucho y no sé si es cierto lo que afirman algunos de sus representantes: que la humanidad ha perdido ya 12 batalla ecológica. No lo sé. Pero lo innegable es que el problema ecológico es muy serio, y que el planeta está gravemente enfermo ante eso, aprende más la lección de que la eficacia débe armonizarse con el respeto también en economía, porque, si no, sólo será una eficacia a corto plazo, que se convierte en dañina a largo plazo. Y hasta andamos buscando normativas que sacrifiquen algo de eficacia a la ecología. Pero claro, cuando nosotros ya nos hemos desarrollado, queremos imponer esas normativas respetuosas a los que están "en vías de desarrollo", a quienes predicamos que deben "darse prisa" para ponerse a nuestro nivel. Y será lógico si ellos nos 
contestan que no están dispuestos a jugar con esa doble baraja y que, si no nos hemos desarrollado todos a la vez, nos hundamos todos a la vez.

\section{El valor-justicia}

Qi os habéis fijado, curiosamente nunca se habla en economía de Ssalario injusto. Sólo se habla de "moderación" salarial. Por supuesto, tampoco se habla de beneficios injustos. (¿Cómo van a ser "injustos" si son "beneficios"?). Se habla sólo de rentabilidad plena o de cosas así. Realmente merecemos el premio Nobel del eufemismo.

Porque la realidad es que el salario mínimo legal en este país es de 58.300 pta.. (que muchas veces no llegan ni para pagar el alquiler de un piso). Y lo decisivo no es si, de hecho, se paga eso (también hay casos de economía sumergida en que aún se paga menos), sino que lo decisivo consiste en que puede pagarse de derecho. ¿'Qué hacemos si, en otros campos diversos del económico una ley permite cosas injustas, aunque se nos diga que, "de hecho", no sucede así? Pues basta ver nuestra reacción ante la llamada "ley Corcuera", por más que el ministro haya dicho que nadie tiene que temer nada, etc., etc. Lo que no toleramos es que se acepte la injusticia como posibilidad legal: porque sabemos muy hien que luego, alguna vez, acaba por pasar al acto.

$Y$ con esto no niego que la moderación salarial sea muv eficaz para invertir, para evitar la inflación. Sólo estoy afirmando que la justicia del salario es un objetivo a cumplir diferente de su libertad, de su uso social o de su legalidad8. Que en economía no hay nada más eficaz que la esclavitud, es una evidencia que se extiende desde el imperio romano hasta la historia de América Latina, tanto, que grandes pensadores occidentales, y hasta teólogos del s. XVII, han querido justificar la esclavitud como una ley de la naturaleza. Y muchos historiadores sostienen que Occidente (capitaneado por Inglaterra) sólo empezó a combatir la esclavitud (después de haberla defendido) cuando los esclavos ya no resultaban rentables para la economía del Imperio, porque no constituían mercado.

Pero si aquí el fin justifica los medios, ¿por qué no va a ocurrir 
lo mismo en los demás campos de la vida?

$\mathrm{Y}$ vamos con el último ejemplo y con uno de nuestros valores más grandes y apreciados.

\section{El valor-diálogo}

$\square$ ste es el gran valor de la democracia. Y uno de nuestros teóri- cos del asunto, N. Bobbio, escribe que, al institucionalizarlo, la democracia"'hace posible la solución de los conflictos sin recurrir a la fuerza9. No obstante, las llamadas filosofías del diálogo suelen apuntar que éste, para ser tal, ha de ser en realidad diálogo "entre iguales", ha de apuntar a unas "condiciones utópicas" de realización, etc.

No discutimos ahora eso. Quisiera notar sólo que en economía no es así: la dinámica del beneficio apunta a dialogar en condiciones de desigualdad para poder salir beneficiado.

Y hay que añadir que "no es así" a pesar de que esa misma es la intuición válida del mercado. Recojo algunas frases que acaba de citar Jordi López en su charla: "El mercado es sólo el instrumento que permite que la eficacia y la moral no entren en contradicción.... Ias economías reguladas fundamentalmente por el mercado, no sólo son las más eficaces, sino que, bien gestionadas, pueden ser las más justas"; es decir, el supuesto fundamental del mercado es que ninguno de los agentes que intervienen en él puede imponer su voluntad a los demás. $Y$, desde este presupuesto, si yo he producido dos mesas y tú has producido cuatro sillas, acabaremos entendiendonos y te cambiaré una de mis mesas por dos de tus sillas. La intuición básica es que, si los dos buscamos lo nuestro y dialogando nos ponemos de acuerdo, saldrá lo más justo.

Pero esa intuición es la que ya no está vigente en los macroniveles, que han pasado del mercado a la imposición. Sólo podría tener vigencia si ambas partes estuvieran en una situación igual y ninguna de las dos pudiera engañar. Pero si esto no se cumple, al buscar lo suyo, uno se comerá al otro.

O con otras palabras aunque se nos repite que estamos en una economía de mercado y se nos cantan sus alabanzas, en realidad no estamos en una economía de mercado, sino en una economía 
de "marketing". Y el "marketing" es exactamente la muerte del mercado.

Aunque no soy economista, me atrevo a sugerir mi sospecha de que esto puede mostrarse de una manera menos descriptiva y más técnica a partir de la evolución de la teoría del valor!. Hasta un profano sabe que el valor es un elemento decisivo para el mercado y que los economistas han discutido mucho para medir objetivamente el valor y poder facilitar el intercambio.

Pues bien, en un principio el valor se medía por las horas de trabajo acumuladas en el producto (medición que puede ser imperfecta, porque olvida la calidad del trabajo). De ahí se pasó a confundir el valor con lo que la gente está dispuesta a pagar por un producto $X$, (lo que introduce un elemento de subjetividad peligroso, porque donde entra la subjetividad puede entrar el engaño). $Y$ de ahí se ha pasado a creer que el valor es "lo que yo consigo sacar" por el' producto, prescindiendo de si la otra parte estaba dispuesta o no a pagarlo.

Y esto mismo puede hacerse gráfico con un ejemplo que muchos conoceréis. Hace pocos días aparecía en El País este diálogo entre los dos muñequitos de Romew: "En realidad no es cierto que las prótesis de silicona produzcan cáncer lo que pasa es que se ha inventado otro tipo de prótesis qué son mucho más caras que las de silicona". Yo no sé si esto es verdad o no: lo que me parece claro es que entra plenamente en la lógica de nuestro sistema. ¡De lo contrario no podría ser material de chiste!

Es decir, con la aparición de las multinacionales se hace imposible la gestión dialogal del mercado. De éste ya sólo nos quedan uno o dos palitos de la " $\mathrm{m}$ " en niveles pequeños. Pero lo que en realidad existe es una planificación central mundial que trasciende todo poder. Como acaba de escribir un conocido economista: "La principal característica de la' economía de mercado es que su objetivo principal no es producir bienes y servicios para satisfacer las necesidades humanas, sino mercancías para ser vendidas y obtener un beneficio"10. Si esto es posible hacerlo satisfaciendo necesidades, pues se hará así también Pero en un mundo desigual no lo es el que no puede pagar no existe para el mercado Ya explicaba Marx que, si en un lugar hay doscientas personas que no tienen 
zapatos, pero tampoco pueden pagarlos, esas personas no existen para el mercado; pero en lugar de no tener un par de zapatos, tienen un par de canas y pueden pagarse lociones y tintes para el pelo, ésas sí que existen para el mercado. Con lo cual es evidente que el mercado no redistribuye (como se nos dice), sino que desequilibra

Cómo habría entonces que recuperar e implantar el valor-diálogo en el mundo de la economía es algo que yo no sé. Aquí me basta con mostrar que está ausente de ella y que esta ausencia puede acabar invadiendo los otros campos (político-culturales) de este valle de lágrimas, haciéndolo más doliente todavía. Yo creo, por del capitalismo es una gran verdad pero no son un ejemplo, que, aunque presumimos mucho de "democracia" y se nos llena la boca con esta palabra, en realidad la democracia está seriamente amenazada, porque la política se está convirtiendo en un "mercado de votos", en el sentido degenerado de esta palabra que acabo de exponer. Las actuaciones de los políticos pretenden mayoritariamente (y a veces exclusivamente) capitalizar más votos: el "máximo beneficio" particular en votos, en lugar de la gestión del país, la cual es sólo un medio para aquello otro. Y los discursos de los políticos se parecen cada vez más a anuncios de televisión o a campañas de marketing, hasta tal punto, que es legítimo sospechar que, en el futuro, quienes hayan de dedicarse a "la cosa pública" ya no estudiarán derecho o ciencias políticas, sino técnicas de mercado y relaciones públicas. . .

Pero es hora de dejar las bromas y pasar a algunas conclusiones.

En mi opinión, lo de las contradicciones culturales del capitalismo es una gran verdad, pero no son un accidente, son un reflejo de sus contradicciones económicas, las cuales se producen porque el capitalismo no busca una armonía de los valores humanos, sino que exclusiviza sólo unos y relega los otros fuera de su ámbito, con lo cual acaba resultado monstruoso.

Y de aquí yo concluiría, bien modestamente, que se nos hace preciso tomar conciencia de tres cosas:

\section{El tejị̂do social está enfermo}

a feliz caída del Este nos significa para nosotros un grito de $\checkmark$ victoria. En la lucha de la ineficiencia absoluta contra la injus- 
ticia clamorosa, era lógico que cayese antes el sistema de la ineficiencia absoluta. Pero esto en modo alguno implica una consagración del enemigo victorioso, como ahora se nos quiere vender. Ya he evocado en otro momento aquella reflexión de San Agustín de que la decadencia de Roma comenzó precisamente el día en que se acabaron los cartagineses.

A todos nosotros nos cuesta aceptar ese dilema que define el pasado inmediato: ineficiencia absoluta versus injusticia clamorosa. Por eso las gentes se decantan por razones, ajenas al problema (sentimentales, militantes o egoístas) diciéndose que el mal del lado querido no es tan grande ("no seria tan ineficaz", "no será tan injusto", etc). Pensemos, pues, que, en el contexto de lo visto en esta charla, todavía no se trata de optar por sistemas sino de optar por valores. Y preguntémonos dónde estamos: si con toda la eficiencia que permita la justicia (lo cual implicará aceptar cierta ineficiencia) o con toda la justicia que permita la eficacia (justicia que entonces tenderá a cero).

Una vez aclarados en esto, no hay inconveniente en reconocer que, a la hora de actuar, la economía se parece al tratamiento de un enfermo incurable (de momento, al menos). Sólo si se acepta la enfermedad, surgirá la voluntad de tratamiento. Si no, estaremos como esos enfermos psíquicos (deprimidos o lo que sea) que constituyen una auténtica cruz para todos los que conviven con ellos, pero que se niegan a ir al médico alegando que ellos están bien sanos y que la culpa la tienen sólo los otros.

$Y$ tampoco habrá inconveniente en reconocer que la enfermedad hace crisis periódicas que pueden reclamar tratamientos nuevos Para volver a tenerla bajo control. Podrá ser legítimo reclamar el abandono de medidas antiguas (como se modifican, vg., las vacunas de la gripe por las mutaciones de los virus etc.), pero es ilegítimo pretender que esas medidas antiguas eran la causa de la enfermedad (como hacen hoy muchos con el keynesianismo) y que su mero abandono ya constituye la salud.

Y que la situación es de enfermedad lo prueba el recentisimo informe del Programa de las Naciones Unidas para el Desarrollo (PNUD), cuyos datos no caben aquí11, por lo que voy a resumirlo en otra conocida frase que servirá de segunda conclusión. 
2. El camino es malo: "ricos cada vez más ricos a costa de pobres cada vez más pobres"

Te elegido deliberadamente esta frase de Juan Pablo ll, no solo 1 porque creo que puede resumir todo el informe citado de las Naciones Unidas, sino porque me parece ilustrativo compararla con otra reciente de Felipe Gonzáles que pudimos conocer por la prensa y la televisión: "en este sistema la eficacia social va junto a la prosperidad económica".

Pues no. Yo me niego a comulgar con esa novela rosa. A lo más, se le podrá responder con una de aquellas clásicas "distinciones" de los escolásticos: si por "eficacia social" se entiende más migajas (incluso bastantes más), "vale". Pero si se entiende mejor redistribución "niego rotundamente". Hablar así es una falsedad interesada para tranquilizar conciencias o es un sueño infantil de que todavía cree en la "armonía preestablecida" de las cosas.

Parece más bien que, en este sistema, la condición sine qua non de la prosperidad económca es precisamente la mala distribución: la famosa "acumulación de capital" siempre se hace con capital de otros: desde el oro de América hasta la moderación salarial de hoy. Y esa riqueza acumulada nunca regresa a quienes la habían producido (al trabajo), sino a quien la utiliza o invierte.

$Y$ esto lleva a una última reflexión conclusiva

\section{3. ¿El fascismo que viene?}

Dor las razones que sea, la percepción no conservadora de que 1 el tejido social está amenazado es una percepción compartida. Tampoco es una percepción tan nueva, puesto que ya debe hacer casi un siglo que Herbent Spencer emitió aquel juicio tan cuidadosamente olvidado: "Nuestro sistema económlco es tremendamente eficaz, Pero necesita cada vez más policía". Y támbien hace su tiempo que Paul Ricoeur escribió (en un articulo dedicado precisamente a la ética económica): "La falta cada vez mayor de fines en una sociedad que aumenta sus medios es, sin duda, la fuente mas profunda de nuestro descontento"12. La vida suele moverse por flujos y reflujos, y luego olvidamos estas cosas que más tarde vuelven a reaparecer más agudizadas. 
Se podría hacer un listado de síntomas que abonarían esa impresión de que estamos en un momento de amenaza del tejido social:

- Según El País del dia 23 de enero de 1992, la depresión acepta al $10 \%$ de nuestra juventud (!), lo cual me parece muchísimo y obliga a preguntarse si es pura casualidad o síntoma de algo.

- La democracia es cada vez menos valorada, porque para la gente joven (que no tuvo que luchar por ella durante tanto tiempo y contra tantas dificultades) se ha convertido en algo simplemente obvio: les pasa lo que me decía hace poco una amiga: "mi hija es de esas que están convencidas de que la televisión ha existido siempre".

- La frase de Ricoeur que acabo de citar se refleja en ese fenómeno del absentísmo político que (a pesar de todas las caídas del leninismo) vuelve a dejarnos en pie la pregunta de Lenin: "libertad ipara qué?"

-Las crisis del capitalismo suelen ser ahora cada vez más largas, y sus remontes cada vez más breves, y ello hace que sus aprovechados vivan cada vez con más sensación de amenaza permanente13.

-Además, asistimos a unos rebotes preocupantes de caudillismo14 y de racismos y fundamentalismos. Y esto no veo yo que tenga vuelta atrás, pues el fenómeno migratorio es absolutamente imparable, por tres razones: a) son millones los dispuestos a morir o emigrar, y ninguna policía puede contra millones; b) nosotros mismos los necesitamos como mano de obra baratísima y para que hagan faenas que ya no estamos dispuestos a hacer, c) los mismos gobiernos los necesitan como Nerón a los cristianos: para convertir en racismo la solidaridad indignada que pueden provocar sus políticas económicas. En esto el ejemplo de Estados Unidos es bien claro: si fuesen sólo pobres, se protestaría a favor de ellos; pero, como son negros, se les maltrata. Luego pensemos en las subidas de Le Pen, de los neonazis, de la liga lombarda... para no hablar de nuestro racismo hispano, que no es de los menores, pero que nos negamos a admitir 15 .

Toda esta acumulación de síntomas sugiere que es real el peli- 
gro de que, al final, acabemos vendiendo nuestra difícil libertad por otro plato de lentejas. Así nacieron los fascismos. Y ahora un fascismo a nivel mundial tendría una salida infinitamente más difícil que cuando se trataba sólo de un fascismo en dos o tres países.

\section{Occidente, jcuidado con perder tu alma!}

Dor eso al dar esta charla a la imprenta un año después, quiero 1 dejar colgada una nueva pregunta: ¿Que es lo que ha triunfado con la caída del Este? ¿Ha ganado la libertad o ha ganado la injusticia? ¿Ha triunfado "el pueblo" o "la nobleza" (económicamente hablando)? Con otras palabras, provocativas: ¿ha caído sólo el telón de acero o también ha caído una nueva "línea Maginot"?

Sin duda alguna, el derrumbe clamoroso de la famosa "línea Maglnot" hacia 1940 puso de relieve la mayor eficacia del nazismo alemán frente a todos los planes militares franceses. Pero, a la larga, fue mostrando también la mayor inmoralidad que estaba en la raíz de esa eficacia. Y cosa muy importante: jesto casi nadie lo veía entonces! La opinlón mayoritaria y triunfante estaba entonces con los invasores, aunque hoy casi nadie esté con ellos. Contra esos invasores, un grupo de creyentes fundó rápidamente, desesperadamente, la revista Témoigna, Chrétien, cuyo primer número, aparecido y vilipendiado en noviembre de 1941, llevaba como título: "Francia, jcuidado con perder tu alma!", y era obra nada menos que de Gaston Fessard.

Ese título me gustaría parafrasearlo hoy: "Occidente, ¡cuidado con perder tu alma". Pero insisto: Entonces su difusión fue mínima y ridiculizada, en comparación con el éxito que tuvo el escrito de respuesta del cura Lecaunier, publicado con censura eclesiástica y todo, donde declaraba que todo el que desobedece a "las autoridades" desobedece a Dios. O en comparación con el miedo del Cardenal Suhard (más tarde "convertido" a la izquierda social), que preguntaba asustado a Gaston Fessard: " ¿no teme Ud. que al combatir el nazismo esté haciendo el juego al comunismo?"16.

Repito que esto hoy puede resultar increíble. Pero entonces era la opinión triunfante y casi general. ¡Qué poco parece haber cambiado la historia! 
Y quiero acabar diciendo que no es que yo sea pesimista. A pesar de todo lo expuesto, creo que la vida tiene unos mecanismos asombrosos de corrección que van sorteando peligros y abriéndose caminos. Estar amenazado no es estar perdido. Y es mejor esperar que esos mecanismos de la vida funcionarán.

Pero quizá pertenece a esos mismos mecanismos (entre otras diez mil cosas) el que nosotros hoy digamos todo lo que aquí se ha dicho.

Notas

1. Recordemos lo que acaba de decir Jordi López: "los neoliberales tienen ciega confianza en que la competividad genera justicia y crean firmemente que el mecanismo competitivo estimula e incentiva el comportamiento no competitivo".

2. Bell escribe expresamente que "estos ámbitos no son congruentes entre si y tienen diferntes ritmos de cambio: siguen normas diferentes que legitiman tipos de conducta diferentes". Y describe así los campos: "economizar significa esencialmente eficiencia, menores costos, mayores beneficios, maximización, optimización y otros patrones de juicio similares... El principio axial del orden político es la legitimidad, y en un orden político democrático es el principio de que sólo puede ejercerse el poder y el gobierno con el consentimiento de los gobernados". Mientras que por "cultura" entiende "el ámbito de las formas simbólicas y, más estrictamente, el campo del simbolismo expresivo que trata de explorar y expresar los sentidos de la existencia humana en alguna forma imagitiva". Para acabar repitiendo que "no existe ninguna relación simple y determinada entre los tres ámbitos" (Las contradicciones cullurales del capitalismo. Madrid 1987, pp. 23-25).

3. La anécdota me resultó tan insignificativa que está aludida en un viejo boletín sobre teología de la liberación en Actualidad Biblografica de Filosofía y Teologia N (1973), p. 375, nota 12.

4. "¡Auri sacra fames, quid non mortalia pectora cogis"!

5. La conquista de América. El problema del ofro. Madrid 1989, p. 154.

6. Tomo el dato de Sal Terrae (febrero 1992), p. 161.

7. La reciente catástrofe de la explosión de gas en Guadalajara, más allá de culpas personales, tiene también una causa estructural y es el precio que ha debido pagar un país en el que, literalmente, no había dinero para gastos de conservación y de mantenimiento, porque todo se lo llevaban los intereses de una deuda ya varias veces pagada. Recuerdo haber comentado alguna vez cómo México, en mis última visitas, me recordaba a muchas casas nuestras de la inmediata postguerra en las que si se rompla la pata de una silla o el cristal de una ventana, no había dinero para arreglarlas y se continuaba así, procurando poner un cartón en la ventana o falcar la mesa como fuera. $\mathrm{O}$ mi madre remendaba mis calcetines agujerados, porque no había dinero 
para cambiarlos.

8. Como andamos todavía con el centenario de la Rerum Novarum, voy a citar dos párrafos suyos que a pesar de que la encíclica es más bien conservadora, resultan hoy de un subversivo subido. "Si el obrero, obligado por la necesidad o acosado por el miedo de un mal mayor, acepta, aun no queriéndola, una condición más dura porque la imponen el patrono o el empresario, esto es ciertamente soportar una violencia contra la cual protesta la justicia" (n. 32). "Deben acordarse los ricos y los amos de que oprimir en provecho propio a los indigentes y menesterosos, y de la pobreza ajena tomar ocasión para la ganancia propia no lo permiten los derechos divinos ni humanos" (n. 14). (Este párrafo comienza reconociendo que para determinar la justicia del salario hay que considerar muchos factores. $Y$ completa esta consideración con una adversativa que introduce el texto citado: pero deben acordarse...).

9. Véase su contribución a la obra de varios autores. Crisis de la democracia. Barcelona 1983.

10. Jesús, ALBARRACIN. La economía de mercado. Madrid 1991. p. 19.

11. Una excelente exposición muy pedagógica y suficientemente amplia la daba el suplemento-revista del diario la Vanguardia del 23 de abril de 1992.

12. Espra (1966), pp. 188-189.

13. Con el agravante de que los deseos no satisfechos irritan más que las necesidades verdaderas no satisfechas. ¡Por eso e rico amenzado resulta más violento que el oprimido!

14. Miguel Roca lo reconocía en La Vanguardia del 6 de diciembre de 1991.

15. También el 6 de diciembre de 1991, una encuesta de El País en el mundo académico revelaba que el $33 \%$ de los profesores y el $50 \%$ de los alumnos se consideran racistas.

16. Cf para esta historia J. LACOUTURE. Jesuites, II, París 1992, pp. 342-373. 